\title{
IMPACTS AND BENEFITS FROM TOURISM AN EXAMPLE FROM THAILAND
}

\author{
Pakin WITCHAYAKAWIN* \\ Naresuan University, International College, 99 Moo-9, Thapho, Mueang, Phitsanulok 65000, Thailand, e-mail: pakinw@nu.ac.th \\ Raktibul CHANTANUPAN \\ Chiang Rai Rajabhat University, School of Tourism, 80 Moo-9, Ban Du, Mueang, Chiang Rai 57100, Thailand, e-mail: raktibul.cha@crru.ac.th
}

\author{
Mosab I. TABASH
}

Al Ain University, College of Business, P.O. Box: 64141 Al Ain, United Arab Emirates (UAE), e-mail: mosab.tabash@aau.ac.ae

\begin{abstract}
Citation: Witchayakawin, P., Chantanupan, R., \& Tabash, M.I. (2020). IMPACTS AND BENEFITS FROM TOURISM AN EXAMPLE FROM
\end{abstract} THAILAND. GeoJournal of Tourism and Geosites, 32(4), 1270-1276. https://doi.org/10.30892/gtg.32412-568

\begin{abstract}
This qualitative research aims to study current impacts and agreement of benefits perceived from tourism in Chiang Saen District of Thailand. This is a case study that collected data by purposive sampling and used structured interview as a research tool. The in-depth interview was conducted with 26 interviewees who are involved in tourism and logistics. The findings illustrate the current impacts covering economic, sociocultural, and environment dimensions. The total impact demonstrates the most positive impact as income generation for investors, with environmental impact being harmful to the area. There are both agreements and disagreements of perceived benefits from tourism and logistics.
\end{abstract}

Key words: Impacts, benefits, tourism, logistics

$* * * * * *$

\section{INTRODUCTION}

Exploring the impact and agreement on the benefits of tourism and logistics in Chiang Saen District of Chiang Rai Province, Thailand, is crucial in border areas where related-tourism businesses and logistics facilities are provided. Tourism is one of the most dynamic business sectors in the world and plays a pivotal role in foreign exchange earnings, while international tourism and worldwide revenue receipts report about $7.3 \%$ of world exports of merchandise and services (Asian Development Bank, 2008). Tourism can be both a driving force for poverty reduction and environmental protection, and makes major contributions to the national economies of countries in the Greater Mekong Subregion (GMS) (Asian Development Bank, 2008). The GMS program has brought about regional collective actions geared for greater connectivity and integration of tourism plans, programs, and strategies among member countries (Asian Development Bank, 2008). The GMS group comprises Cambodia, Lao People's Democratic Republic, Myanmar, Guangxi Zhuang Autonomous Region and Yunnan Province in the People's Republic of China (PRC), Vietnam and Thailand (Asian Development Bank, 2008).

There was steady growth in the number of tourist arrivals and revenue among GMS countries between 2018 and 2019 , as reported by World Tourism Organization (UNWTO, 2020). Thailand presented the highest number of tourist arrivals at 38.2 million in 2018, climbing up to 39.8 million in 2019, with the percentage of change being $4.2 \%$. Cambodia in 2018 had 6.2 million tourists, 3.7 million in Lao PDR, and 3.5 million in Myanmar (UNWTO, 2020). Vietnam illustrated the biggest increase between 2018 and 2019 at $16.2 \%$ (UNWTO, 2020). Based on revenue from tourism, Thailand received the largest share at US\$ 56,366 million in 2018, and US\$ 60,521 million in 2019, a 3.2\% rise (UNWTO, 2020). In 2018, Vietnam gained US\$ 10,080 million, followed by US\$ 4,352 million in Cambodia, US\$ 1,652 million in Myanmar, and US\$ 734 million in Lao PDR (UNWTO, 2020). Surprisingly, Myanmar displayed the most significant growth of revenue at approximately 50.3\% between 2018 and 2019 (UNWTO, 2020). By comparing the number of tourist arrivals and revenue among GMS countries (specific data only the South East Asia countries) in 2018 and 2019 , Thailand is the most popular destination which is indicated by the highest number of both tourists and revenue.

Chiang Saen is a pioneer city of tourism among GMS members for many reasons. CSC is the largest Mekong port after the river departs China, and mostly serves as the main turnaround point for cargo ships moving products between PRC and Thailand throug h the culturally rich CSC which was once the capital of the Lanna Kingdom, with the old city wall and ancient Buddhist mon uments still visible (UNWTO, 2016). Chiang Saen's high-quality pier serves as the terminus for passenger vessels transporting to and from Yunnan and there are good opportunities for cruise tourism as there is a daily longboat service to and from Sop Ru ak River, or cruising to Chiang Khong for crossing into Lao PDR (UNWTO, 2016). A border of the GMS in Thailand is Chiang Saen District in Chiang Rai Province, where border tourism and logistics cross the countries. Chiang Saen City (CSC) is an ancient city founded in the $13^{\text {th }}-14^{\text {th }}$ century (MOTS, 2019b); and it is located approximately 60 kilometers to the North of Chiang Rai city and about 891 kilometers from Bangkok. The charm of Chiang Saen is its location by the stunning and peaceful Mekong River among the convergence of Thailand, Myanmar and Laos (Yaprasit, n.d.). There are a number of highlighted tourist sites, including the Golden Triangle Viewpoint, the Golden Triangle Park, the Hall of Opium, and the huge gold Buddha image. However, there is no precise information of the number of visitors and receipts in CSC, only the information for the entire Chiang Rai Province as presented by the Ministry of Tourism and Sports (MOTS, 2019a). The total number of visitors was 460,097 in 2018 and 471,596 in 2019, an increase of 2.50\% in Chiang Rai Province (MOTS, 2019a). The number of Thai visitors was greater than the number of foreign visitors in both years.

However, the growth rate for the number of foreign visitor was larger than the number of Thai visitors (MOTS, 2019a). The total revenue from all visitors in 2018 was US\$ 129.2 million and US\$ 130.8 million in 2019, steadily rising by about $1.25 \%$. The growth of revenue from foreign visitors being $0.51 \%$, while it was $1.43 \%$ from Thai visitors (MOTS, 2019a). The increasing changes of visitor number and revenue in Chiang Saen District are based on tourism database in Chiang Rai Province between 2018 and 2019.

\footnotetext{
${ }^{*}$ Corresponding author
} 


\section{Statement of the Problem}

It is estimated that in the Mekong River Basin climate change provided $82.29 \%$ of the total streamflow change between 1992 and 2009, and human activities caused 62\% of the total change between 2010 and 2015 (Li et al., 2017). Based on the results of Li et al. (2017), the current study would like to explore the exact components of the human activities as a cause of the impact. Lertrit (2016) explained that local people in CSC had no cooperation with the government officials in the Cultural Resource Management (CRM) project, and had failed to understand the information value of the ancient site as they did not have a sense of ownership for the cultural property. However, local people were ready and willing to support the CRM project if they felt they would have a beneficial stake in the CRM program, and any cooperation as well as assistance from residents would be a possibility (Lertrit, 2016). It appears that the sense of ownership is based on cooperation and assistance between government officials and local people. Based on the results of Lertrit (2016), the current study would like to investigate the agreement of benefits from tourism and logistics businesses because the benefits can fill the sense of belonging and ownership for the locals in CSC.

\section{Research Objectives, Questions, and Benefits of the Study}

The current study tries to achieve the following objectives: (1) to study the current impact of tourism and logistics in Chiang Saen District of Thailand; and (2) to identify the agreement of benefits more than costs of tourism and logistics in Chiang Saen. The research questions are:

(a) What are the current impacts of tourism and logistics in Chiang Saen District of Thailand?

(b) How can local people agree on benefits more than costs of tourism and logistics in Chiang Saen? The results of this study will be of benefit for the Chiang Saen Government (CSG), to consider the issue of the supportive development policies for border tourism and logistics under the perception of locals on tourism and logistical impacts, and the agreement of benefits.

\section{LITERATURE REVIEW}

Social exchange theory (SET) suggests that residents are likely to participate in exchange to support tourism development until the perceived benefits of tourism exceed the perceived costs of tourism. The social behaviour of humans in economics is undertaken by incorporating economics, psychology, and sociology based on SET (Homans, 1958). SET posits that all human relationships are formed by the use of subjective cost-benefit analysis and the comparison of alternatives (Homans, 1958). SET is an exchange of material goods but also non-material ones (Homans and Rex, 1961). The elements of SET are (1) social rewards and value of rewards and (2) equity and distributive justice, rewards and value of rewards [social rewards, costs, and profit] (Homans and Rex, 1961). Based on SET, there are a number of tourism impact and tourism development studies such as the following:

The economic, social, cultural, and environmental factors are likely to affect residents' perceptions of tourism and their willingness to participate in an exchange to support for or against tourism development (Yoon et al., 2001). Both positive and negative economic impacts as well as negative environmental impacts were identified as significant contributors to how residents assess perceived benefits resulting from the development of gaming (Kang et al., 2008). The theoretical approach of this study infers that SET is related with both 'impact' and 'benefit'; due to benefit or profit being a factor to encourage people exchanging (participating) in society; and benefit is a component in positive economic impact. There are some studies which support that the study of impacts and benefits are involved. A case in Indonesia, the number of Karamba, (a local term describing a floating net cage), is reduced in order to limit the ecological impact on the Lake Maninjau area (Firdaus et al., 2019). However, the reduction of Karamba affected the income of Karamba farmers; thus, to increase economic benefits, Karamba is now used as a tourist attraction showing that tourism can contribute to the social and economic benefits to local communities and to maintain environmental sustainability at the same time (Firdaus et al., 2019).

In Chiang Saen, there is the potential of river tourism which should generate benefits for locals. There is a huge potential in river tourism on the upper Mekong River that it is not run by central government, but the people of Chiang Rai Province. It was a type of river tourism they consider best fits with the current needs of tourists. Thus, river tourism on the upper Mekong is something unique to Chiang Rai Province but no positive attitude has so far been shown by the local authorities (Amnuay-ngerntra and Hideki, 2013). Paraskevaidis and Andriotis (2017) revealed that reciprocal altruism (the basis for some socially acceptable activities such as volunteering, charity, philanthropy, and blood donation) is one of several motives for participating in voluntary tourism association. Altruistic Surplus Phenomenon is more adequate that SET to interpret the study groups' social behavior (Paraskevaidis and Andriotis, 2017).

Chiang Saen is a city which not only attracts tourists for ancient ruins and river tourism but this city is also a logistics hub because of its strategic location at Thailand's border connecting the GMS members. There are several accepted definitions of logistics. Logistics is defined as a supply change orientation, from point-of-origin to point-of-consumption; while logistics management is defined as the process of planning, implementing, and controlling the efficient, cost-effective flow and storage of raw materials, in-process inventory, finished goods, and related information flow from point-of-origin to point-of-consumption for the purpose of conforming to customer requirements (Council of Logistics Management, 1986). Logistics is a part of the supply chain process that plans, implements, and controls the efficient, effective flow and storage of goods, services, and related information from the point-of-origin to the point-ofconsumption in order to meet customers' requirements (Council of Logistics Management, 1998). Likewise, logistics is defined as the management of inventory in motion and at rest and that the goal of the logistics manager is to achieve the lowest level of investment in inventory consistent with ensuring customer service and maintaining efficient production (Delaney, 1996). Further, focusing on the customer service area within logistics, it is defined as a process which takes place between the buyer, seller, and third party (Lalonde et al., 1988). Customer service is a critical component of any definition of logistics or logistics value (Rutner and Langley, 2000). Thus, customer service is also related with tourism logistics. In Chiang Saen, tourism logistics is also a crucial business.

For tourism logistics at the level of tourism towns which are related to the tourist service (Tourism Supply Chain Operation) is involved in the three flows or movements - physical flow, information flow, and financial flow (Sanyanunthana and Benabdelhafid, 2016). Physical flow refers to travel, transportation, baggage, transport of tourists, and convenience of travel; while information flow refers to giving news and information, guideposts, place signs, information on how things should be done in some places, and warning of dangers for the tourist (Sanyanunthana and Benabdelhafid, 2016). Financial flow refers to facilitation of goods payment or tourism services, and buying various kinds of travel ticket (Sanyanunthana and Benabdelhafid, 2016). Based on the purpose of this study, 'logistics' refers to tourism logistics which is focusing on transportation and the logistics is a part of tourism. Transport was the most crucial source of environmental hazards in the logistics system (Aronsson and Brodin, 2006; Wu and Dunn, 1995). The concerning environmental impact was discussed in terms of measurements of emissions of carbon dioxide caused by the use of transport veh icles and other strategic logistics decisions with their emissions (Abukhader and Jonsson, 2003; Aronsson and Brodin, 2006; Wu and Dunn, 1995). 


\section{MATERIALS AND METHODS}

This empirical study is qualitative research by the case study approach. The data were collected in September 2019 from 26 key informants in the area of study near the border and the center area of CSC. The key informants are subjects who are impacted by tourism and logistics and benefits received, including government officers, travel agency managers and staff as well as villagers. Data collection method is face to face in-depth interview for 25 key informants and video call interview for 1 subject by purposive sampling technique. Research tool is a structured interview form with the question guidelines as the following:

Q1: Please explain the current situation of Chiang Saen with regard to tourism and Logistics.

Q2: What do you think about the current positive impact from tourism and logistics on the economy at Chiang Saen?

Q3: Please explain the current positive impact from tourism and logistics on socio-culture at Chiang Saen

Q4: How do you explain about the current positive impact from tourism and logistics on the environment at Chiang Saen?

Q5: Please provide information about the current negative impact from tourism and logistics on economy at Chiang Saen

Q6: How do you feel about the current negative impact from tourism and logistics on socio-culture at Chiang Saen?

Q7: Please give some details about the current negative impact from tourism and logistics on environment at Chiang Saen

Q8: Please explain any other impact from tourism and logistics

Q9: How do you perceive the overall impacts of tourism and logistics in Chiang Saen? (Kang et al., 2008).

Q10: Do you agree or disagree that the benefits of tourism and logistics are greater than the costs to the people in Chiang Saen? Please explain (Kang et al., 2008).

Data were analyzed by open coding in ATLAS.ti. ATLAS bears on the idea of mapping the world by an archive of meaningful documents; and the abbreviation ' $t i$ ' in the software name refers to text interpretation (Friese, 2014). ATLAS.ti belongs to the genre of Computer-Aided Qualitative Data Analysis Software (CAQDAS) program (Friese, 2014). ATLAS.ti was selected for use in this study for several reasons based on the authors' experience. First, it impressively provides a multicolor coding network presentation (as shown in Figure 1) as compared to Nvivo program which provides only one color. Second, it gives the 12 options of network layouts which is more than Nvivo gives (only 4 options - layered directed graph, hierarchical, circle, and directed). Third, it provides many choices of explanations of relationships between one code and another code e.g., it contradicts, is a property of, is a cause of, and is a part of; but Nvivo provides only one explanation of relationships. Lastly, ATLAS.ti is a more stable system for data storage because in Nvivo all data is instructed by the system to be removed before updates, but in ATLAS.ti, the data is not removed in any case. The analysis process consists of five steps by: (1) Preparing data in word file: to decode data from sound record and interview form by listening and reading data, then typing into word file; (2) Grouping data: to group data by topic and sub-topic, e.g. Impact is a topic and a positive economic impact is a sub-topic; (3) Open coding: to insert data file into Atlas.ti program and create codes of data; (4) Categorizing data: to categorize data by counting frequency of codes; (5) Thematizing: to theme data at final process.

\section{RESULTS AND DISCUSSION}

This section presents a demographic profile of the key informants, impacts and benefits of tourism and logistics as well as discussion. The total of key informants is 26 subjects. Most of them are male $77 \%$, and female 23\%. The age of the informants is 30 to 59 years old $73 \%, 29$ or lower $23 \%$, and 60 or above $4 \%$, respectively. Most of them have educational level in college or bachelors $46 \%$, followed by high school or lower $42 \%$, and master or above $12 \%$. Most of the interviewees work in the business sector $65 \%$, in government sector $19 \%$, and other $16 \%$.

\section{Impacts of Tourism and Logistics}

This sector presents the impacts of tourism and logistics in CSC and perceived total impacts of the key informants. The impacts of tourism and logistics were studied in three dimensions - economic, socio-cultural, and environmental impacts.

Table 1. The Codes of PECI and NECI

\begin{tabular}{|c|c|c|}
\hline Group & Codes & $\mathbf{F}$ \\
\hline \multirow{15}{*}{ PECI } & Lot of Chinese visitors at GT - good product selling & 2 \\
\hline & Tour and logistics make good income from China & 1 \\
\hline & Work travelers make good income in service and logistics & 1 \\
\hline & More trading establishment & 1 \\
\hline & Municipality gets income from customs and tax & 1 \\
\hline & Local products more selling & 1 \\
\hline & Lao people influx buying products in CS, chemical products in Laos & 1 \\
\hline & Getting more support fund & 1 \\
\hline & Increase investment of tourism better economy & 1 \\
\hline & High fruit export to China & 1 \\
\hline & Laos visitors come only Sunday - good & 1 \\
\hline & Export higher volume & 1 \\
\hline & Good tourism - locals get income by serving transport & 1 \\
\hline & SMEs get income & 1 \\
\hline & Total PECI & 15 \\
\hline \multirow{13}{*}{ NECI } & Low visitors make poor economy & 4 \\
\hline & Lesser volume of selling products & 4 \\
\hline & Unfairness in income distribution & 3 \\
\hline & Not good to import fruit and products from China - fake - chemical & 2 \\
\hline & High competition in product selling & 2 \\
\hline & Risk investment if products not in accord with Chinese demand & 1 \\
\hline & Low water level in river made slow down economy & 1 \\
\hline & Income is not good & 1 \\
\hline & Some tourism and logistics business close by slow down world economy & 1 \\
\hline & Product price is expensive & 1 \\
\hline & Only investors got benefits & 1 \\
\hline & High investment cost of products and plus rental of shops & 1 \\
\hline & & 22 \\
\hline
\end{tabular}


The current study divided tourism impacts into six sections based on the study of Polnyotee and Thadaniti (2015), including positive social impact, positive environmental impact, positive economic impact, negative social impact, negative environmental impact and negative economic impact. The codes and the frequency (F) of positive economic impacts (PECI) and negative economic impacts (NECI) are presented in Table 1.

Table 1 reveals the codes of PECI and NECI as well as frequency. 'Lot of Chinese visitors at GT - good product selling' as the highest frequency code (2) in PECI, while other codes have only 1 frequency of each. There are several categorizations of the code frequencies in NECI, 'Low visitors to make poor economy' and 'Lesser volume of selling products' (4), 'Unfairness in income distribution' (3), and 'Not good to import fruit and products from China - fake - chemical' and 'High competition in product selling' (2), respectively. Thus, the number of visitors is a primary factor to determine a good economy in CSC. The number of tourists is a significant factor to retain the status of tourism management as mentioned in the tourism development theory. Tourism development theory identified seven stages - (1) exploration, (2) inclusion, (3) enlargement, (4) exacerbation, (5) renewal, (6) stagnation, and (7) downturn (Butler, 1980). The exacerbation stage pointed out the number of tourists is still growing and marketing tools were used to prolong the tourist season to attract more tourists. Thus, marketing is a factor to retain the stage of exacerbation. The CSC needs to find out the exact tourism product identity and the outstanding service in logistics which are significant factors for marketing creation. The dynamic marketing and promotion were strategies as a pull factor to motivate the demand of the visitors that accorded with the statement of Yu and Turco (2000). If destination managers well-promoted a special event, it could be a powerful strategy for boosting the local tourism industry (Yu and Turco, 2000). Besides, the special events and activities may be created as in the case at Victoria Falls, that the economic benefits came from tourist activity development (Tichaawa and Mhlanga, 2015). The high number of visitors affects good economic impacts by high volume of shopping and consumption payment; however, communities are confronted with threats of the visitors. Chinese visitors were nor mally held in a positive light in relation to the purchase and use of local products, transport, and lodges (Gong et al., 2019). The next results reveal the codes of positive socio-cultural impacts (PSOI) and negative socio-cultural impacts (NSOI) as shown in Table 2.

Table 2. The Codes of PSOI and NSOI

\begin{tabular}{|c|c|c|}
\hline Group & Codes & $\mathbf{F}$ \\
\hline \multirow{14}{*}{ PSOI } & Locals care more about conservation in culture & 4 \\
\hline & Visitors like visiting the ancient city & 1 \\
\hline & Visitors enjoy joining Loy Krathong Festival (Lantern) - alert economy & 1 \\
\hline & Local venders have more Chinese demand & 1 \\
\hline & Logistics makes exchange in social activities - import - export - makes good economy & 1 \\
\hline & Local people can live in the community with visitors & 1 \\
\hline & Visitors enjoy inspecting school events and parades & 1 \\
\hline & Thai food promotion by selling to Chinese visitors & 1 \\
\hline & CSC has diverse ethnicities as good cultural products & 1 \\
\hline & Ageing people get free transport traveling in the city & 1 \\
\hline & Temples, traditions and culture make income from tourism & 1 \\
\hline & Locals have more participation in tourism activities & 1 \\
\hline & Increase number of taxis between ancient city to GT and Maesai & 1 \\
\hline & $\begin{array}{c}\text { Total PSOI } \\
\end{array}$ & 16 \\
\hline \multirow{16}{*}{ NSOI } & Chinese visitors don't respect rules \& have poor manners (impolite dress, danger driving, smoking) & 2 \\
\hline & Unlawful activities - stealing, gambling & 2 \\
\hline & Social change and mixed culture - change dressing, service style & 2 \\
\hline & Public areas were used by street venders & 1 \\
\hline & Taxi services make local transport lose income & 1 \\
\hline & Venders cater to Chinese demand but ignore locals & 1 \\
\hline & Different religious beliefs make it difficult to cooperate & 1 \\
\hline & Investors from outside buy land or boats and change the lives of locals & 1 \\
\hline & Online gambling from casino & 1 \\
\hline & Children may copy impolite dressing from outsiders & 1 \\
\hline & Most Chinese visitors smoke which can affect our children & 1 \\
\hline & Ancient ruins get destroyed reducing their value & 1 \\
\hline & Social problems from imported laborers who don't respect rule & 1 \\
\hline & Chinese visitors are careless and cause accidents on roads & 1 \\
\hline & Criminal cases from visitors & 1 \\
\hline & Total PSOI & 18 \\
\hline
\end{tabular}

Table 2 shows the codes of PSOI and NSOI and frequency. 'Locals care more about conservation in culture' is the top frequency (4) in PSOI, while 'Chinese visitors don't respect rules and have poor manners - impolite dress, dangerous driving, and smoking', 'Unlawful activities - stealing, gambling', and 'Social change and mixed culture - change dressing, service style' with 2 frequencies are the top in NSOI. Hence, more conservation impacted local behaviors, while locals got negative impacts from Chinese visitors. Chinese tou rists as a core group of visitors in CSC who expressed behaviors e.g., non-respect of local rules, unpleasant manners, impolite dressing, dangerous driving, breaking smoking rules, and non-cleanliness of the public toilet related with the findings of Gong et al. (2019). The residents in Bangkok highlighted a perceived lack of respect by Chinese visitors for local laws and customs, e.g., drinking, smoking, or being loud in public areas (Gong et al., 2019). The next findings display the codes and the frequency (F) of positive environmental impacts (PENI) and negative environmental impacts (NENI) as shown in Table 3.

Table 3 reveals the codes in PENI and NENI, and frequency. 'Good development of infrastructure and city' is the highest frequency code (4) and followed by 'Construct colorful and neat buildings' code (2) in PENI. At the same time, 'Increase volume of garb age in river and on land' is the top frequency code (4), followed by 'Oil leakage from boats', 'More chemicals in agriculture products government no control', and 'More chemical seeps into air and rivers' code with 3 frequencies. So, tourism and logistics developed infrastructure and CSC, but the city and people encountered more garbage, polluted water and air, and chemicals. The key informants perceived overall impacts by everyday observation and their senses because they live in CSC. Further, locals received information of impacts from news, social media, meetings, and discussion. For example, the positive economic impact - they knew that ducks and meat as well as ready-to -eat pineapple were in high demand to Chinese markets. They retained these products to sell, and then changed their 
behavior of eating fish by eating duck and meat. Minced raw meat is the identity and favorite food in their community that the Chinese markets impacted and changed local behaviors. The key informant also perceived a positive economic impact by inspection of the accommodation invoices and the high number of guests which was evidence of high income in hotel business and entrepreneurs received even more income from logistics. For negative impacts, locals often saw and smelt dead animals floating in the river. Finally, the roads in the areas of the Golden Triangle are too narrow which is a negative aspect. Infrastructure development in CSC is an effect from tourism and logistics that accorded with the findings of La Rocca (2005), that town planning should contribute to ameliorate the urban quality of life by forming plans of action to manage the urban transformations due to the introduction of new urban demand. The CSC has been affected from the chemical leakage in the river and air which causes burning in the nose and eyes, this is a serious environmental impact that the government need to be concerned about and develop law enforcement to control this impact.

\section{Table 3. The Codes of PENI and NENI}

\begin{tabular}{|c|c|c|}
\hline Group & Codes & $\mathbf{F}$ \\
\hline \multirow{8}{*}{ PENI } & Good development of infrastructure and city & 4 \\
\hline & Construct colorful and neat buildings & 2 \\
\hline & Convenient transportation and good roads & 1 \\
\hline & Have campaigns to protect against mosquitoes & 1 \\
\hline & Shops were developed - more convenient to shop & 1 \\
\hline & Environment conservation for tourism & 1 \\
\hline & Logistics make orderly city & 1 \\
\hline & $\begin{array}{r}\text { Total PENI } \\
\end{array}$ & 11 \\
\hline \multirow{18}{*}{ NENI } & Increase volume of garbage in river and on land & 4 \\
\hline & Oil leakage from boats & 3 \\
\hline & More chemicals in agriculture products - government no control & 3 \\
\hline & More chemical seeps into air and rivers & 3 \\
\hline & Arbitrary throw away garbage and spitting by Chinese & 2 \\
\hline & Chinese visitors don't keep the toilets clean & 2 \\
\hline & People in upper countries left dead animals in rivers & 1 \\
\hline & Deforestation and covered by cement at Casino areas & 1 \\
\hline & Chinese block river water, keeping water to use in casino & 1 \\
\hline & Environment continuously changing because of Chinese investors & 1 \\
\hline & Develop riverbank for tourism and cruise has affected fish stocks & 1 \\
\hline & Removal of rock for boating & 1 \\
\hline & Casino drained wastewater to Mekong River - not clean for bathing & 1 \\
\hline & Air pollution from vehicles & 1 \\
\hline & Destroy nature to make new roads accessing new houses & 1 \\
\hline & Visitors cut and pick flowers & 1 \\
\hline & Public fishing areas change to be private areas & 1 \\
\hline & Total NENI & 28 \\
\hline
\end{tabular}

\section{Perceived Benefits and Costs}

The perception between the benefits and costs of tourism and logistics in CSC. The codes and a network of the agreements are presented in Figure 1.

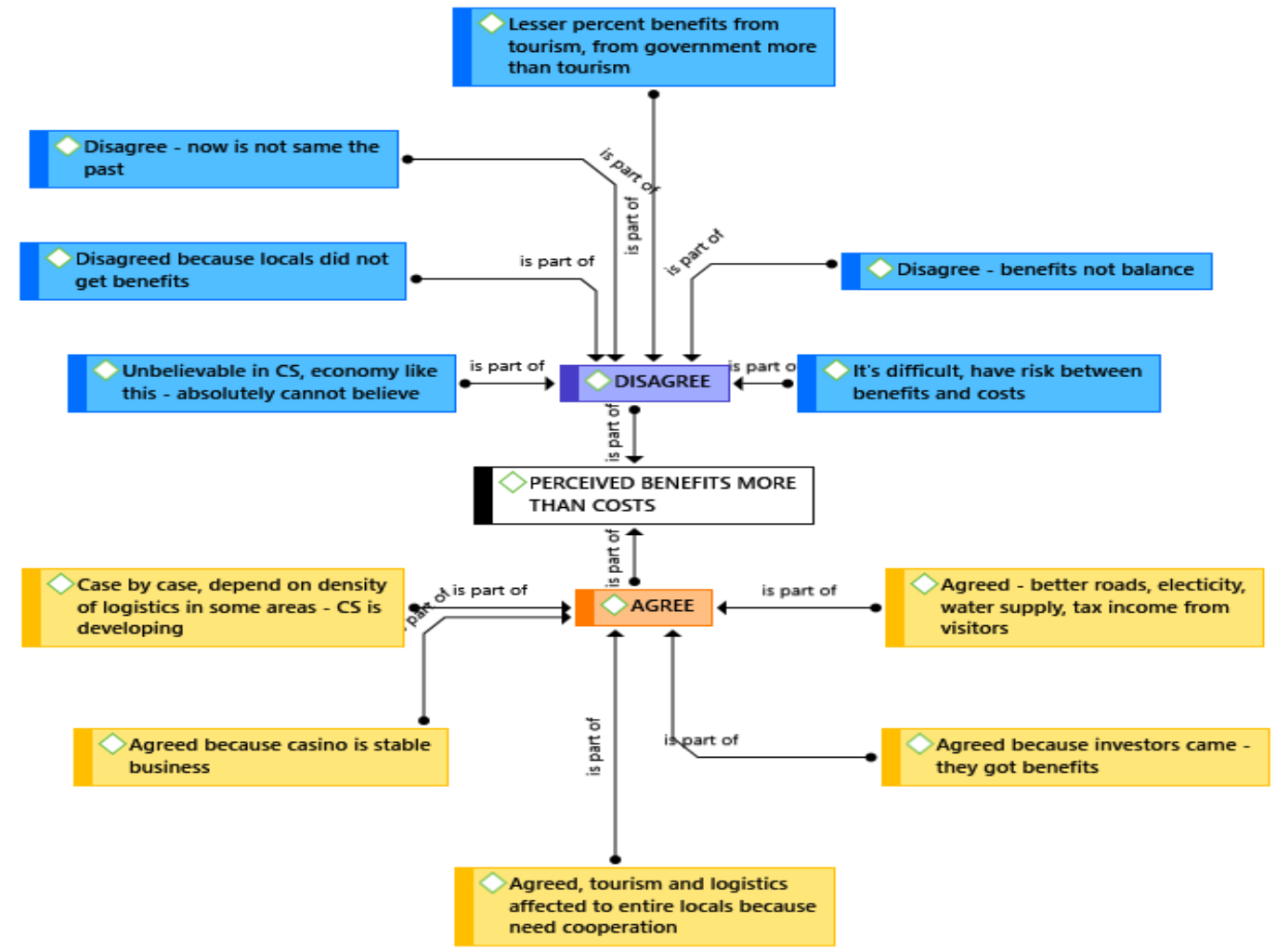

Figure 1. Perceived Benefits and Costs (Source: Authors' own work, 2020) 
Figure 1 displays the perceptions of key informants and the codes are grouped to be agree and disagree. The findings show the agreement and disagreement with reasons. These results can be a summary of overall impacts that the key informants were concerned with and encountered in this area. The codes and frequencies are shown in Table 4.

Table 4. The Codes of Perceived Benefits and Costs

\begin{tabular}{|l|l|c|}
\hline Group & \multicolumn{1}{|c|}{ Codes } & F \\
\hline \multirow{4}{*}{ Agree } & Agreed because investors came - they got benefits & 2 \\
\cline { 2 - 3 } & Agreed - better roads, electricity, water supply, tax income from visitors & 1 \\
\cline { 2 - 3 } & Case by case, depend on density of logistics in some areas - CSC is developing & 1 \\
\cline { 2 - 3 } & Agreed because casino is stable business & 1 \\
\cline { 2 - 3 } & Agreed tourism and logistics affected all locals because of the need for cooperation & 1 \\
\cline { 2 - 3 } & & $\mathbf{6}$ \\
\hline \multirow{5}{*}{ Disagree } & Total Agree & 1 \\
\cline { 2 - 3 } & Disagree - benefits not balance & 1 \\
\cline { 2 - 3 } & Lower percentage of benefits from tourism, from government more than tourism & 1 \\
\cline { 2 - 3 } & Disagree - now is not similar in the past & 1 \\
\cline { 2 - 3 } & Disagreed because locals did not get benefits & 1 \\
\cline { 2 - 3 } & Unbelievable the economy in CSC is as bad as this & 1 \\
\cline { 2 - 3 } & \multicolumn{1}{|c}{ Total Disagree } & $\mathbf{6}$ \\
\hline
\end{tabular}

Table 4 demonstrates the codes of agreements in the benefits and costs of tourism and logistics in CSC. Both sides - agreement and disagreement are presented in the same frequencies (6). Indeed, the agreed side indicates 'agreed because investors came - they got benefits' as 2 frequencies that the code is more significant than others. So, the direction of these findings will be modified in the discussion section. The villagers in CSC have more cooperation which has the effect of tourism and logistics benefits. This statement argues the findings of Lertrit (2016) which indicated locals in CSC had no cooperation with government officials in the CRM project, had failed to understand that the archaeological ruins belong to the government, the government's responsibility for looking after the ruins, as well as not having a sense of ownership for the cultural property (Lertrit, 2016). Based on SET (Homans, 1958), people who perceived benefit gain and social equity liked to cooperate and participate in society which related with the current findings. The benefits had a relationship with the support tourism development that is claimed by SET and they affected decisions regarding communication and relationship of people interaction (Kang et al., 2008; Yoon et al., 2001). Based on the results, the benefits of tourism and logistics in CSC belong to only entrepreneurs and large organizations such as the casino, which was not balanced in CSC. Likewise, key informants indicated disagree more significant than agree of a higher benefit than costs in tourism and logistics as they mentioned unfair benefit distribution and not believing they would get higher benefits. The fairness of benefit distribution needs to be taken into consideration as locals have strong feelings about this. Strong feelings were also expressed that there should be legitimacy in relation to resource distribution and tourism benefits (Palmer and Chuamuangphan, 2016).

\section{CONCLUSION, IMPLICATION AND LIMITATION}

The current economic impacts in CSC confront a slow-down of the economy due to the decrease of visitors who are significant shoppers who influence economic status. The income distribution in the entire area is not balanced. The local people have more concern about conservation of the ancient ruins and culture as tourism products in their community, even though the communities encounter unpleasant behaviors of Chinese visitors, social changing by multi-cultures, and illegal goings-on in CSC. There is a good development of infrastructure in CSC, but there is a rising volume of garbage in the city, oil leakage into the river, chemicals in agric ultural products which leak out to the air and rivers. Additionally, Chinese visitors' behaviors affect the cleanliness in the areas.

The perception of benefits and costs of the tourism and logistics in CSC indicated more benefits than costs to entrepreneurs, however benefits were less among communities. The Thai government needs to take serious action and have inter-country agreement of the impact that has been created by the use of chemicals in Lao agriculture, as the chemicals leak into the air and rivers and have a ne gative environmental impact which affects CSC. The CSG needs to issue some policies to make a more balanced income distribution, add Chinese language information boards throughout CSC, for directions and important regulations as well as law enforcement to control the threats from visitors to communities and reduce the negative socio-cultural impacts. The issue of stronger GMS law- enforcement concerning the environment care may help to increase the responsibility of logistics about vessels' condition to prevent oil leakage into the river. There is a limitation of data triangulation that should be collected by observation and evaluated again by a survey method.

\section{ACKNOWLEDGEMENT}

Authors are grateful to Chiang Rai Rajabhat University for providing the research development fund [B36011034/2017]. The study would not be success without this great support.

\section{REFERENCES}

Abukhader, S., \& Jonsson, G. (2003). The evironmental implications of electronic commerce: a critical review and framework for future investigation. Management of Evironmental Quality. An International Journal, 14(4), 460-476

Amnuay-ngerntra, S., \& Hideki, S. (2013). Developing River Tourism on the Upper Mekong: Challenges and Opportunities. European Journal of Business and Social Sciences, 1(10), 36-51.

Aronsson, H.H., Brodin, M.H., \& Huge Brodin, M. (2006). The environmental impact of changing logistics structures. The International Journal of Logistics Management, 17(3), 394-415. https://doi.org/10.1108/09574090610717545

Butler, R.W. (1980). The concept of a tourist area cycle of evolution: implications for management of resources. Canadian Geographer, $24(1), 5-12$.

Delaney, R.V. (1996). Seventh Annual State of Logistics Report. St. Louis, MO

Firdaus, F., Shalihin, N., Anggreta, D.K., Yasin, F., \& Tutri, R. (2019). Improving the benefits of karamba into tourism activities: An effort to reduce the ecological impact of aquaculture in Maninjau Lake, Indonesia. GeoJournal of Tourism and Geosites, 26(3), 726-736. https://doi.org/10.30892/gtg.26304-392

Friese, S. (2014). Qualitative Data Analysis with ATLAS.ti. (K. Metzler, Ed.) (2nd ed.), London, Sage.

Gong, J., Detchkhajornjaroensri, P., \& Knight, D.W. (2019). Responsible tourism in Bangkok, Thailand: Resident perceptions of Chinese tourist behaviour. International Journal of Tourism Research, 21(2), 221-233. https://doi.org/10.1002/jtr.2256

Homans, G.C. (1958). Social Behavior as Exchange. American Journal of Sociology, 63(6), 597-606. https://doi.org/10.1086/222355 
Homans, G.C., \& Rex, J. (1961). Social Behaviour: Its Elementary Forms. The British Journal of Sociology (Vol. 13). New York: Harcourt, Brace \& World, Inc. https://doi.org/10.2307/587952

Kang, S.K., Lee, C., Yoon, Y., \& Long, P.T. (2008). Resident perception of the impact of limited-stakes community-based casino gaming in mature gaming communities, 29, 681-694. https://doi.org/10.1016/j.tourman.2007.07.011

La Rocca, R.A. (2005). Mass Tourism and Urban System: Some Suggestions to Manage the Impacts on the City. Tourism, 3(1), 8-17. Retrieved from http://ertr.tamu.edu8http//ertr.tamu.edu

Lalonde, B.J., Martha, C.C., \& Thomas, G.N. (1988). Customer Service: A Management Perspective. Chicago, IL.

Lertrit, S. (2016). Conservation and Management of Archaeological Sites Who owns the past? A perspective from Chiang Who owns the past ? A perspective, 5033(May). https://doi.org/10.1179/cma.1997.2.2.81

Li, D., Long, D., Zhao, J., Lu, H., \& Hong, Y. (2017). Observed changes in flow regimes in the Mekong River basin. Journal of Hydrology, 551, 217-232. https://doi.org/10.1016/j.jhydrol.2017.05.061

Palmer, N., \& Chuamuangphan, N. (2016). Societal values and local responses to ecotourism amongst villagers in Chiang Rai, Thailand. Sheffield Hallam University Research Archive. Retrieved from http://shura.shu.ac.uk/14939/

Paraskevaidis, P., \& Andriotis, K. (2017). Altruism in tourism: Social Exchange Theory vs Altruistic Surplus Phenomenon in host volunteering. Annals of Tourism Research, 62, 26-37. https://doi.org/10.1016/j.annals.2016.11.002

Polnyotee, M., \& Thadaniti, S. (2015). Community-based tourism: A strategy for sustainable tourism development of Patong Beach, Phuket Island, Thailand. Asian Social Science, 11(27), 90-98. https://doi.org/10.5539/ass.v11n27p90

Rutner, S.M., \& Langley, C.J. (2000). Article information: Logistics Value:Definition, Process and Measurement. The International Journal of Logistics Management, 11(2), 73-82. https://doi.org/http://dx.doi.org/10.1108/09574090010806173

Sanyanunthana, K., \& Benabdelhafid, A. (2016). The Value Added Tourism Logistics Industry of Thailand. Journal of Tourism \& Hospitality, 4(5). https://doi.org/10.4172/2167-0269.1000187

Tichaawa, T.M., \& Mhlanga, O. (2015). Residents' perceptions towards the impacts of tourism development: the case of Victoria Falls , Zimbabwe. African Journal of Hospitality, Tourism and Leisure, 4(1).

Wu, H., \& Dunn, S. (1995). Environmentally reponsible logistics systems. International Journal of Physical Distribution \& Logistics Management, 25(2), 20-38.

Yaprasit, S. (n.d.). ลายเชียงแสน [Design of Chiang Saen]. (M. Yaprasit, Ed.). Chiang Rai, กลุ่มรักษ์เชียงแสน, Thai.

Yoon, Y., Gursoy, D., \& Chen, J. S. (2001). Validating a tourism development theory with structural equation modeling. Tourism Management, 22(4), 363372. https://doi.org/10.1016/S0261-5177(00)00062-5

Yu, Y., \& Turco, D.M. (2000). Issues in tourism event economic impact studies: The case of the Albuquerque International Balloon Fiesta. Current Issues in Tourism, 3(2), 138-149. https://doi.org/10.1080/13683500008667870

*** Asian Development Bank. (2008). Tourism Sector in the Greater Mekong Subregion. Operation Evaluation Development. Manila, Philippines. Retrieved from https://www.oecd.org/countries/mongolia/42221951.pdf

*** Council of Logistics Management. (1986). What's It All About? Oak Brook, IL.

*** Council of Logistics Management. (1998). Annual Business Meeting. Anaheim, CA. Retrieved from www.CLM1.org

*** MOTS. (2019a). Domestic Tourism Statistics (Classify by region and province 2019). Retrieved March 29, 2020, from https://www.mots. go.th/more_news_new.php?cid=525

*** MOTS. (2019b). Tourism Route on R3A Connecting Thailand, Lao PDR and China. Bangkok: Chulalongkorn University Press. Retrieved from https://www.mots.go.th/mots_en/download/Research/RouteR3AEnglishResize.pdf

*** UNWTO. (2016). Mekong River-based Tourism Product Development. Retrieved May 18, 2019, from https://www.e-unwto.org/doi/pdf/10. $18111 / 9789284418015$

*** UNWTO. (2020). World Tourism Barometer (Volume 18, Issue 4). Madrid. Retrieved from https://www.e-unwto.org/doi/epdf/10.18111/ wtobarometereng.2020.18.1.4

$\begin{array}{llll}\text { Article history: } & \text { Received: } 19.06 .2020 & \text { Revised: } 29.08 .2020 & \text { Accepted: 02.10.2020 onailable online: } 16.10 .2020\end{array}$

